\title{
ANALYSING STUDENTS' PERSPECTIVES ON GEOMETRY LEARNING FROM THE COMBINATION OF VAN HIELE PHASE-BASED INSTRUCTIONS AND GEOGEBRA
}

\author{
Georgina Ling Ling Chua ${ }^{1}$, Khairul Amilin Tengah ${ }^{2}$, Masitah Shahrill ${ }^{3}$, Abby Tan ${ }^{4}$ \\ and Elvynna Leong 5 \\ ${ }^{1}$ Berakas Secondary School, Ministry of Education,Brunei \\ ${ }^{2,3}$ Sultan HassanalBolkiah Institute of Education, Universiti Brunei Darussalam, Brunei \\ ${ }^{4,5}$ Faculty of Science, Universiti Brunei Darussalam, Brunei
}

\begin{abstract}
Geometry has always been regarded as one of the most important area in Mathematics. The van Hiele model is one of the renowned theories focusing on the teaching and learning of geometry. While GeoGebra is a free, open-source dynamic geometry software developed to assist the teaching and learning of Mathematics in general. This study investigated the effectiveness of van Hiele phases with GeoGebra in geometric transformations, particularly for the topic of rotation in geometry. Some of the Year 11 students who participated in this study were interviewed. The focus of the interview was directed at exploring the students' views on van Hiele phase-based learning, the use of GeoGebra and the thought processes on the topic. The development of the interview analyses yielded two emerging themes namely, the impact of van Hiele phases and the impact of GeoGebra as an instructional tool. Although the combination was mainly perceived as positive, there were also reluctance in accepting due to the readjustment needs of the concepts and applications of the tool itself.
\end{abstract}

Keywords: Geometry, Van HieleModel, Geogebra, Students' Perceptions

\section{Introduction}

The van Hiele theory derived from two Dutch educators, Dina and Pierre van Hiele, with the intention to explain and identify students' difficulties in geometry (Mason, 2009). They introduced the existence of levels and a teaching structure based on the five van Hiele phases. Alex and Mammen (2012) stated that determining students' performance in geometry was beneficial through the use of van Hiele theory as it could pin down the aspects that attributes to these difficulties. The van Hiele phases also provide an easier alternative for students to grasp the abstract nature of geometry. The van Hiele theory is currently the best model used to define students' level of thinking in geometry (Battista, 2002). It is a framework used to identify students' geometric levels as well as to provide instructions to help students' progress from one level to the next (Fuyset al., 1988).

Abdullah and Zakaria (2011) mentioned that activities following van Hiele's approach of learning were more structured and coordinated. The van Hiele phases form a system of instruction, which starts with the teacher driving the lessons through investigation of simple examples, and gradually progressing towards problemsolving activities that demand student initiative, thereby, indicating that each van Hiele phase serves a different and significant purpose (Serow, 2007). Many studies globally, for example, in Hong Kong (Liu, 2005), India (Chang and Bhagat, 2015), Malaysia (Abdullah and Zakaria, 2013a) and Turkey (Kutluca, 2013) had shown that the implementation of van Hiele phase-based learning in classrooms yields positive outcomes in students' performance in geometry.

Corresponding Author: Masitah binti Shahrill/ masitah.shahrill@ubd.edu.bn 
In order for students to advance from one level to the next, they must go through five phases in sequence, starting from information, followed by guided orientation, explicitation, free orientation and lastly, integration. The five phases are explained in detail in Table 1. Some students might require need to go through several phases for more than one cycle in order to attain new knowledge on a particular topic (Choi-Koh, 2000; Mason, 2009). Hence, this meant that it would take a considerable amount of time for the students to attain the next level. This concurred with van Hiele-Geldof's statement (1957, as cited in Usiskin, 1982) that the progress from one level to another does not happen in the span of one lesson or a short period of time. Although the movement of levels does not occur instantly, it must be noted that the five phases of learning are important in assisting development. Therefore, for any geometric topic, it must first be arranged according to the respective levels and then incorporate these phases into every subtopic taught. On the other hand, the development of students' VHL relies on their comprehension of geometric content over time.

Table 1 Five phases of learning in van Hiele theory

\begin{tabular}{|c|c|}
\hline Phases & Description \\
\hline Information & Students explore and familiarise with the subject matter. \\
\hline Guided Orientation & Students perform tasks that require the formation of variety relations. \\
\hline Explicitation & $\begin{array}{l}\text { Students discover the relations, attempts to demonstrate this realisation into } \\
\text { expressions and associate this to learning technical language. }\end{array}$ \\
\hline Free Orientation & $\begin{array}{l}\text { Students learn by performing more complex tasks in order to discover the } \\
\text { network of relations through his/her methods. }\end{array}$ \\
\hline Integration & $\begin{array}{l}\text { Students summarise and reflect on their individual learning and actions on } \\
\text { the specific subject matter to achieve an overview on the newly network of } \\
\text { relations. This phase could be done as a discussion or task (Abdullah and } \\
\text { Zakaria, 2013b). }\end{array}$ \\
\hline
\end{tabular}

In education, specifically in Mathematics, various research studies on dynamic geometry software such as GeoGebra, Geometer's SketchPad and Cabri are on the rise. This is highly attributed to the vast amount of features available in this dynamic geometry software. GeoGebra was the dynamic geometry software utilised in this study. GeoGebra was designed to cater to a wide variety of content areas in Mathematics of all levels ranging from primary to university level (Hohenwarteret al., 2008). Since its use is targeted to people of all ages, its functions can be operated easily. Moreover, GeoGebra is a free, open-source dynamic geometry software developed to assist the teaching and learning of Mathematics. As GeoGebra can be used offline, it is easy to access and can be placed as a supplementary tool for teaching and learning in classrooms.

The geometric stages are split into five successive levels: visualisation (VHL 1), analysis (VHL 2), informal deduction (VHL 3), formal deduction (VHL 4) and rigour (VHL 5). There are two types of numbering systems: VHL 0 to VHL 4 which was used in the original work by van Hiele and VHL 1 to VHL 5 which was adapted by the Americans (Vojkuvkova, 2012). In the latter case, Clements and Battista (1992) suggested an existence of VHL 0 called pre-recognition. At this level, they proposed that students couldn't distinguish shapes due to the limited spatial visualisation ability. Table 2 illustrates the representation of each level with its respective examples in a hierarchical structure, including VHL 0. 
Proceeding of the $3^{\text {rd }}$ International Conference on Education, Vol. 3, 2017, pp. 205-213

Table 2 Modified version of the hierarchical structure of VHL

\begin{tabular}{|c|c|}
\hline Levels & Examples \\
\hline $\begin{array}{l}\text { Pre-recognition } \\
\text { (VHL 0) }\end{array}$ & $\begin{array}{l}\text { Students cannot distinguish geometric concepts due to lack of visual ability. } \\
\text { Example: Students cannot differentiate between a triangle with a square. }\end{array}$ \\
\hline $\begin{array}{l}\text { Visualisation } \\
\text { (VHL 1) }\end{array}$ & $\begin{array}{l}\text { Students can discern geometric concepts solely based on appearance. } \\
\text { Example: Students recognise transformations as a movement and a change } \\
\text { in figures. }\end{array}$ \\
\hline $\begin{array}{l}\text { Analysis } \\
\text { (VHL 2) }\end{array}$ & $\begin{array}{l}\text { Students can analyse and identify the properties of geometric concepts. } \\
\text { Example: Rotation is where the object and image are congruent to each } \\
\text { other, possess the same orientation, etc. }\end{array}$ \\
\hline $\begin{array}{l}\text { Informal Deduction } \\
\text { (VHL 3) }\end{array}$ & $\begin{array}{l}\text { Students can logically interrelate the properties of geometric concepts. } \\
\text { Example: Students can use the properties to locate the exact position of the } \\
\text { rotated image. }\end{array}$ \\
\hline $\begin{array}{l}\text { Formal Deduction } \\
(\text { VHL } 4)\end{array}$ & $\begin{array}{l}\text { Students can substantiate theorems and establish relationships between } \\
\text { them. } \\
\text { Example: Students can prove that the object and the rotated image are } \\
\text { congruent to each other. }\end{array}$ \\
\hline $\begin{array}{l}\text { Rigour } \\
\text { (VHL 5) }\end{array}$ & $\begin{array}{l}\text { Students can comprehend the relationships of these different theorems. } \\
\text { Example: Students can apply rotation on any three-dimensional figures and } \\
\text { find the exact position of the rotated image. }\end{array}$ \\
\hline
\end{tabular}

\section{The Study}

The aim of this study was to investigate the effectiveness of van Hiele phases with GeoGebra in geometric transformations, particularly for the topic of rotation in geometry.Only two Year 11 classes were selected as part of the study. From the sample of 33 mixed-ability students aged 14-17 years old, a total of seven students were interviewed. Pencil and paper test was given as pre-test and post-test for the purpose of measuring changes in performance, selection of students for interview and test script analysis to support finding. However, in this paper, only the interview will be discussed as the data collection and analysis. Prior to the intervention, all students took the prescribed test to determine their Van Hiele level.

\section{Semi-structured Interviews}

According to Atebe (2008), interviews are a better approach as opposed to paper-and-pencil tests in probing and analysing students' responses because it helps to attain a greater amount of information of students' thoughts. In this study, semi-structured interviews were carried out as the quantitative data. In semi-structured interviews, an outline is often produced in advance with regard to the subject matter that was to be investigated in order to provide a clearer structure for the interviewer (Kroli, 2008). However, during the interview process, the format can be altered to ensure that that only relevant information could be obtained. The focus of the interviews were directed at exploring students' views on van Hiele phase-based learning, use of GeoGebra and thinking processes on the topic to help clarify the difficulties faced in the tests.

For the interviews, students' achievements were divided into three categories, namely, low, average and high based on their test results. Each category consisted of equally divided marks, where low, average and high achievers equates to an achievement between $0 \%$ to $33 \%, 34 \%$ to $66 \%$ and $67 \%$ to $100 \%$, respectively. Then, the selection of students was purposive in nature. This was to provide flexibility in the research and ensure that a better representation of students' opinions was gathered. An equal number of students from each group were chosen, depending on the availability of students classified in these categories. Subsequently, one-to-one interview sessions were carried out to further enrich the quantitative data. The duration of each interview was 
approximately 20 to 30 minutes. Efforts were taken to ensure that any external factors such as noise were kept minimal. Additionally, students were allowed to talk in their mother tongue (Malay language) if they felt more comfortable. All interviews were audio-recorded and transcribed. The interviews were conducted in a fixed area to ensure the settings were kept consistent. Additionally, the interviews that were transcribed was analysed by gathering emerging themes from students' responses. The use of interviews supplied a greater depth and dimension to provide a richer set of data in investigating the effectiveness of van Hiele phases by incorporating GeoGebra.

\section{Results and Discussions}

Prior to the selection of students for interviews, students were grouped into their respective categories (low, average and high) based on their test achievement. In order to acquire equal representatives and ensure an optimum amount of information was gathered, three students from each category (high and average) were chosen. In total, there were seven students involved in the interviews. The profiles of these students are listed in Table 3. By developing thorough analyses of interviews, two emerging themes were gathered namely, impact of van Hiele phases and impact of GeoGebra as an instructional tool.

Table 3 Students' profiles selected for interviews

\begin{tabular}{lccc}
\hline Student & Gender & Van Hiele Levels & Students achievement \\
\hline A & Male & 3 & High \\
B & Male & 2 & High \\
C & Female & 2 & High \\
D & Female & 1 & High \\
E & Female & 1 & Average \\
F & Male & 1 & Average \\
G & Female & 1 & Average \\
\hline
\end{tabular}

\section{Theme 1: Impact of van Hiele Phase}

From the interviews, it was gathered that the traditional chalk-and-talk method of teaching had been the main medium of instruction that were used to teach the topic on rotation. The tools that were commonly used to assist teachers in teaching the topic were compass and protractor. As a result of chalk-and-talk teaching approach, some students experienced difficulties in learning the topic. One of the main difficulties was the lack of comprehension of the topic, which was strongly associated with the delivery of the content. To further intensify the problem, students expressed that teachers constantly focused on relaying the content through direct instruction without paying close attention to the needs of the students. Teaching by dictating and questionanswer techniques inhibits the development of students thinking skills (Erdogan et al., 2009).

According to the van Hiele theory, students of lower levels cannot comprehend the learning materials taught at a higher level of knowledge. From this, competency in language is the foundation in comprehending this knowledge. Lack of language competence is commonly known as the barrier that obstructs students' abilities in performing well. Setati (2008) stated that the language used is pivotal for learning and thinking and communicating mathematically is a key to teaching and learning mathematics in school. Majority of the students expressed that they were able to comprehend the language used in the classroom as the teacher progress from one lesson to next. However, a significant problem was detected for those students that were not able to the make sense of the language used, that is, lack of proficiency in the English language. Thus, this meant that the mathematical terms that were used in the lessons, for example, the concept of 'congruent' and 'similarity' was difficult to grasp. 
From both interviews and test scripts, the thought processes of students could be clearly determined. The properties of rotation which was the learning content allocated to level 2 were investigated. Many students were not able to specify the properties without much difficulty. They could only mention certain key terms without clearly justifying the relations of the keywords. Hence, it was difficult to accurately identify the meaning of their incomplete sentences. By probing further in the interviews, students managed to elaborate their answers, to a certain extent. The different responses of students were listed in Table 2. It was clearly observed that terms such as 'object' and 'image' were rarely mentioned, indicating that there was limited use of precise terminologies. With this limited knowledge on properties of rotation, it accurately verified students' difficulty in gaining full acquisition of level 2 questions in both pre-test and post-test.

Table 4 Examples of students' responses on the properties of rotation

Students' responses

Same shape and same size, same direction, same length

Same shape and the direction, then angle, centre

Same shape, same distance of image from the centre as well as the object and the angle is the same

Congruence

The properties are the shape of the triangle is the same to that image, the distance between the origin to the image is the same and the direction is the same if we go anticlockwise or clockwise

Same size, same shape. It's called congruence. Same orientation. After that, it has same angle, and the direction. It has a direction

By discussing the sequence of the lesson that occurred, four students expressed similar part of the lessons that was the most effective for them, as shown in Figure 1. Three students (Student A, Student B and Student C) stated that the most effective part of the lesson was performing the worksheet. This was categorised as the transition of learning process from GeoGebra onto paper. In terms of van Hiele's phases, this particular part of the lesson was identified to be integration. However, in this study, this was regarded as the first part of the integration phase. The students explained that it was the most effective as they were able to incorporate everything that they have learnt in the previous phases and they were able to perform it by themselves. This meant that students were more inclined towards active and independent learning in the classroom. On the other hand, Student F stated that implementing the use of GeoGebra to verify his answer that he had attempted in the worksheet was effective. By relating this to van Hiele phases, this was the second part of the lesson that was associated with integration. This showed that this student was able to perform on both the worksheet and GeoGebra. The ability of integrating these two ways implied that the student felt strongly positive about learning through this method.

Student A: Because we attempt the worksheets that were given by ourselves

Student B: So that I can have experience how to do it

Student $C$ : Um the one where you ask us to do the exercise

Student F: The most effective is when checking the answers on GeoGebra because it uh it helps the accuracy or the angle to find really easy

Figure 1 Students' views on the most effective part of the lesson.

As shown in Figure 2, the phase that Student G found to be effective was deduced as the guided orientation phase. She found the instruction following traditional method were to no effect. However, the use of GeoGebra as an instructional tool allowed her to be more engaged with the lesson as she could follow through the learning content much easier. Moreover, GeoGebra helped her to portray a clear relationship of all the lessons taught, hence, making the learning materials simpler to comprehend. 
Student G: You guide

Interviewer: And then why was it effective to you?

Student G: Because easy to understand, more simple

Figure 2 Excerpt indicating Student G's preference of van Hiele phase.

In the free orientation phase, students were in charge of their own learning within their groups as they could decide the shape of the object, centre of rotation, angle of rotation and direction among themselves. Most of the students found that the additional time given to explore with the use of GeoGebra was helpful. It allowed them to communicate with their peers to discuss their findings. Additionally, Student F stated "Because, I, um if I draw something, I believe it is a challenge for me so it's probably a question to figure out where the position is." This denoted that this particular student maximised the time given to challenge himself as well as his group members by constructing random shapes in GeoGebra. As a result of this, they could learn from each other and seek help from their peers if they faced any difficulties in using GeoGebra.

However, two students (Student D and Student E) showed similar concerns working in a group especially in the free orientation phase. Their responses were presented in Figure 3. They expressed that majority of the group members tend to rely on a single member to perform the tasks that he/she wished, while the others watched. The rest of the group members did not provide any input to the task. Distribution of tasks was not equally divided within the group and thus, they did not discuss or share ideas together to predict the outcomes. This meant that these students did not use this phase to their advantage. In spite of this, it should be noted that GeoGebra creates a diverse range of opportunities for students to freely explore to allow effective learning. Guven (2012) stated that learning transformations by incorporating all the necessary components into the students' own design induces an advanced comprehension of transformations.

Student D: Sometimes it's not because they're not working

Student E: It's hard for us because when one tries, the others can't. So all of us pushed the task to one another and became lazy

Figure 3 Students' concerns on group work.

\section{Theme 2: Impact of GeoGebra as an Instructional Tool}

Some students portrayed a positive attitude towards the use of GeoGebra. They perceived that learning the topic on rotation through GeoGebra as fun. They thoroughly enjoyed the learning environment created by GeoGebra. Furthermore, they felt that learning through the implementation of GeoGebra in the lessons had greatly benefitted them in different ways, as elicited by the students in Table 5. These positive responses concurred with a vast majority of studies (Shadaan and Leong, 2013; Mainali, 2014; Rajagopalet al., 2015), in which students reacted positively towards learning with GeoGebra. Therefore, the usefulness of GeoGebra was not denied in this study. It had greatly assisted the development of students' competency in answering questions on rotation.

Table 5 Students' opinions on the advantages of using GeoGebra 
Georgina Ling Ling Chua, KhairulAmilin Tengah, MasitahShahrill, Abby Tan andElvynna Leong/ Analysing Students '

Perspectives on Geometry Learning from the Combination of Van Hiele Phase-Based Instructions and GeoGebra

\begin{tabular}{ll}
\hline Advantages & Students' opinions \\
\hline Visual & If it's in the classroom, what's that, the whiteboard, can't really see the \\
& movement, then if it's in the ICT, we know where it turns and using ICT is easy to \\
see the angle of rotation, like 90 degrees, it's very easy. & It's 100 percent correct though. \\
Accuracy & It's help me, easy for me to use to find the angles that I don't know. \\
Ease of use & It shows the answer then easy to understand. \\
Effectiveness &
\end{tabular}

Undoubtedly, one of the most frequent responses was the ability to clearly visualise the materials that were being studied. The responses for observing dynamic motion of rotation were well received by the students. Both Student E and Student F were impressed with the visuals and their comments were shown in Figure 4. This denotes that instilling a solid concept of rotation was possible through the use of GeoGebra. Thereby, the properties and the relationship of the object and image can be easily observed and simultaneously, the incorporation of GeoGebra could accelerate the learning process.

Interviewer: Amazed? Why are you amazed?

Student E: Because it's unique, like it's a new concept for us so we were surprised (translated version)

Student F: ... I was surprised that it can um uh position in different angles which is hard to find with normal hands to use

Figure 4 Students' opinions on the visuals provided in GeoGebra.

Despite acknowledging certain advantages of GeoGebra, some students remained skeptical towards its use. They preferred the traditional method of instruction in the classroom rather than supplementing instruction with GeoGebra. These students were identified to be those who were less technologically oriented. They were not familiar and felt unconfident in using GeoGebra due to the lack of IT skills. They criticised that the exposure to GeoGebra caused a sudden change in the method of instruction, which made them feel uncomfortable, as they had always been used to the traditional method of teaching throughout their education. In other words, they were resistant to change. Thus, they had difficulty coping in a new learning environment. These students have also stressed that they were not keen in using GeoGebra nor would they give a second chance in using GeoGebra to aid them in learning geometry in the future. They would rather perform it on paper for practice, in the same way as the conduct of examinations.

Connolly (2010) stated that geometric transformations are strongly dependent on visualisation. This indicates that the incorporation of GeoGebra as a teaching tool in van Hiele phase-based instruction was helpful. The clear visuals largely contributed to the increase in students' ability in comprehending the topic on rotation, which would not have been possible through the traditional method of teaching. Hence, this meant that GeoGebra played a significant role in helping to clarify the properties that were not clearly visible on the whiteboard. This is in accordance with the study conducted by Sahaet al. (2010), in which they stated that GeoGebra provides a medium of learning through visualisation, which stimulates learning and further strengthen comprehension. This shows a promising potential of the use of GeoGebra in teaching and learning geometry in school.

\section{Conclusions}

The use of GeoGebra as an instructional tool in a classroom had received both positive and negative feedbacks from the students. With the sudden implementation of GeoGebra, it was understandable that students perceived negatively on its use. This was because they need to readjust to the concepts and applications with the use of 
Proceeding of the $3^{\text {rd }}$ International Conference on Education, Vol. 3, 2017, pp. 205-213

GeoGebra within a short time span. Moreover, the implementation of GeoGebra disrupted the normal flow of the lessons that the students have been used to. In spite of these negative perceptions, there was an increase in the students' results from their test results. Therefore, it can be said that students' responses did not signify the ineffectiveness of GeoGebra as an instructional tool. Instead, students perceived the learning of rotation via GeoGebra to be unfavourable. It was believed that visuals had greatly contributed to the increase in students' performance. Consequently, this study suggested that the exposure of the dynamic feature of GeoGebra in a mathematics classroom had significantly helped students with visualisation. Visualisation is a crucial element necessary to conceptualise the idea of rotation. In other words, the ability to visualise is a stepping-stone to improving students' comprehension in the topic.

According to the students' responses gathered from interviews, it had been established that the learning environment with GeoGebra was not suitable for every student. It is the nature of life that no one type of the instruction can satisfy all the students' varied learning needs (Halat, 2007). To address this issue, alternative approaches must be continuously explored to accommodate different types of learning. However, it must be reiterated that visualisation plays a very important role in learning rotation. Therefore, the use of instructional tools that enhances visualisation must be emphasised in the classroom. As an example, a similar study can be done using physical manipulatives such as acetate paper. Through the influence of acetate paper in rotation, majority of the students perceived that it has facilitated their learning and visualisation (Enkí, 2014). The learning environment provided by hands-on learning such as acetate paper can be less intimidating for those students who did not favour GeoGebra. Since they are required to perform the activities in their classroom, there is no need for them to manipulate their ways through the unfamiliar GeoGebra and can be more at ease. Therefore, this extended research can help to pin point the method that is regarded as the most acceptable by the students to be implemented in future classrooms.

\section{References}

Abdullah, A. H., and Zakaria, E., 2011, Students'perceptions towards the van Hiele's phases of learning geometry using geometer's sketchpad software. Australian Journal of Basic and Applied Sciences, 5(7), 787792.

Abdullah, A. H., and Zakaria, E., 2013a, The effects of van Hiele's phases of learning geometry on students' degree of acquisition of van Hiele levels. Procedia - Social and Behavioral Sciences, 251-266.

Abdullah, A. H., and Zakaria, E., 2013b, Enhancing students' level of geometric thinking through van hiele's phase-based learning. Indian Journal of Science and Technology, 6(5), 4432-4446.

Alex, J., andMammen, K., 2012, A survey of South African grade 10 learners' geometric thinking levels in terms of the van Hiele theory,Anthropologist, 14(2), 123-129.

Atebe, H. U., 2008, Students' van Hiele levels of geometric thought and conception in plane geometry: A collective case study of Nigeria and South Africa.Unpublished PhD thesis, Rhodes University.

Battista, M., 2002, Learning geometry in a dynamic computer environment. Teaching Children Mathematics, 8(6), 333-339.

Chang, C., andBhagat, K., 2015, Incorporating GeoGebra into geometry learning - A lesson from India. Eurasia Journal of Mathematics, Science and Technology Education, 11(1), 77-86.

Choi-Koh, S. S., 2000, The activities based on van Hiele model using computer as a tool. Journal of the Korea Society of Mathematical Education Series D: Research in Mathematical Education, 4(2), 63-77.

Clements, D. H., and Battista, M. T., 1992, Geometry and spatial reasoning. In: Handbook of Research on Mathematics Teaching and Learning, edited by D. A. Grouws.(New York: Macmillan), pp. 420-462.

Connolly, S., 2010, The impact of van Hiele-based geometry instruction on student understanding. Unpublished Master thesis, St. John Fisher College. Date of access: 05/06/2016. http://fisherpub.sjfc.edu/mathcs_etd_masters/97

Enkí, K., 2014, Effects of using manipulatives on seventh grade students' achievement in transformation geometry and orthogonal views of geometric figures. Unpublished Master thesis, Middle East Technical University. Date of access: 08/06/2016. http://etd.lib.metu.edu.tr/upload/12617286/index.pdf 
Georgina Ling Ling Chua, KhairulAmilin Tengah, MasitahShahrill, Abby Tan andElvynna Leong/ Analysing Students'

Perspectives on Geometry Learning from the Combination of Van Hiele Phase-Based Instructions and GeoGebra

Erdogan, T., Akkaya, R., andÇelebiAkkaya, S., 2009, The effect of the van Hiele model based instruction on the creative thinking levels of $6^{\text {th }}$ grade primary school students. Educational Sciences: Theory \& Practice, 9(1), 181-194.

Fuys, D., Geddes, D., andTischler, R., 1988,The van Hiele model of thinking in geometry among adolescents. Reston, VA: National Council of Teachers of Mathematics.

Guven, B., 2012,Using dynamic geometry software to improve eight grade students' understanding of transformation geometry. Australasian Journal of Educational Technology, 28(2), 364-382.

Halat, E., 2007, Reform-based curriculum \& acquisition of the levels. Eurasia Journal of Mathematics, Science \& Technology Education, 3(1), 41-49.

Hohenwarter, J., Hohenwarter, M., and Lavicza, Z., 2008, Introducing dynamic mathematics software to secondary school teachers: the case of GeoGebra. Journal of Computers in Mathematics and Science Teaching, 28(2), 135-146.

Kroli, T., 2008, Focus on Disability: Trends in Research and Application (Hauppage, NY: Nova Science Publishers).

Kutluca, T., 2013, The effect of geometry instruction with dynamic geometry software; GeoGebra on Van Hiele geometry understanding levels of students. Educational Research and Reviews, 8(17), 1509-1518.

Mainali, B. R., 2014, GeoGebra from students' perspectives. GeoGebra International Journal of Romania, 3(1), 31-38.

Mason, M., 2009, The van Hiele levels of geometric understanding. Professional Handbook for Teachers, Geometry: Explorations and Applications. Date of access: 12/05/2016.http://jwilson.coe.uga.edu/EMAT8990/GEOMETRY/mason,\%20marguerite.\%20the\%20van\%20hie le\%20levels\%20of\%20geometric\%20understanding.\%202002.pdf

Rajagopal, S. A., Ismail, Z., Ali M., and Sulaiman N., 2015, Attitude of secondary students towards the use of GeoGebra in learning loci in two dimensions. International Education Studies, 8(13), 27-32.

Saha, R. A., Ayub, A. F. M., and Tarmizi, R. A., 2010,The effects of GeoGebra on mathematics achievement: enlightening coordinate geometry learning. Procedia Social and Behavioral Sciences, 8(1), 686-693.

Serow, P., 2008, Investigating a phase approach to using technology as a teaching tool. In:Navigating Currents and Charting Directions, edited by M. Goos, R. Brown, and K. Makar.Paper presented at the Proceedings of the $31^{\text {st }}$ Annual Conference of the Mathematics Education Research Group of Australasia, The University of Queensland, Brisbane, 28 June - 1 July(Adelaide, Australia: MERGA), pp. 445-452.

Setati, M., 2008, Access to mathematics versus access to the language of power: the struggle in multilingual mathematics classroom. South African Journal of Education, 28(1), 103-116.

Shadaan, P., and Leong, K. E., 2013, Effectiveness of using GeoGebra on students' understanding in learning circles. The Malaysian Online Journal of Educational Technology, 1(4), 1-11.

Usiskin, Z., 1982,Van Hiele Levels and Achievement in Secondary School Geometry (Chicago: University of Chicago).

Van Hiele-Geldof, D., 1957,The didactics of geometry in the lowest class of the secondary school. Unpublished doctoral dissertation, University of Utrecht.

Vojkuvkova, I., 2012, The van Hiele model of geometric thinking. In: WDS'12 Proceedings of Contributed Papers: Part I - Mathematics and Computer Sciences, edited byJ. Safrankova and J. Pavlu. (Prague: Matfyzpress), pp. 72-75. 